\title{
Abordagem sistêmica para uma análise do design do livro impresso, digital e hiper-livro
}

\author{
Systemic approach to an analysis of the design of printed, digital and hyper-digital books
}

FIGUEIREDO, Luiz Fernando Gonçalves de I Doutor em Engenharia de Produção

Universidade Federal de Santa Catarina -UFSC I Iff@cce.ufsc.br

FERREIRA, Alais Souza I Mestranda em Design

Universidade Federal de Santa Catarina - UFSC I alais.ferreira@live.com

BORTOLAN, Giovana Mara Zugliani I Mestranda em Design

Universidade Estadual de Santa Catarina - UDESC I gmzugliani@gmail.com

OURIVES, Eliete Auxiliadora Assunção I Doutora em Engenharia de Produção

Universidade Estadual de Santa Catarina - UDESC I elieteourives@gmail.com

SILVA, Carina Scandolara da I Doutoranda em Design

Universidade Federal de Santa Catarina - UFSC I cariscan@gmail.com

\begin{abstract}
Resumo
Por muitotempo os livrosimpressos foramaúnica Abstract

ferramenta de apoio ao ensino-aprendizagem, porém com o avanço da tecnologia surgiram os livros digitais que, além de constituírem repositórios de conteúdo específico, também possibilitaram o desenvolvimento de novos formatos e a conexão com outras bases. O objetivo proposto para este trabalho foi selecionar três suportes de livros identificados como: impressos, digitais e hiper-livros e analisar as diferenças em relação ao design a partir de uma abordagem sistêmica. Com isso, buscou-se verificar se há necessidade de adaptação e aprimoramento para ajustá-los aos

For a long time, printed books were the only tools to support teaching-learning, but as technology advanced digital books emerged. In addition to being content-specific repositories, they also enabled the development of new formats and the connection with other bases. This work begins with the selection of three books of different formats: printed, digital and hyper-digital. Then, the differences in relation to the design were analyzed from a systemic approach. The aim was to verify if there is a need for adaptation and improvement to fit the various existing devices and if the existing supports are complementary or substitutive between them.
\end{abstract} vários dispositivos existentes e, se os suportes existentes são complementares ou substitutivos entre si.

Keywords: Design. Design of the book. Systemic approach.

Palavras-chave: Design. Design para livro. Abordagem sistêmica. 


\section{INTRODUC̣ÃO}

Em tempos de transformações desencadeadas pelo aumento de tecnologias e mudanças comportamentais dos consumidores, o Design vem ampliando seu campo de atuação de maneira que este não se restringe somente a elaboração e produção de um produto, mas está presente em todas as fases do processo produtivo.

Para este novo olhar do design pôde-se entender o processo como sendo uma abordagem sistêmica, ou seja, o estudo global dos sistemas de forma a envolver todas as suas interdependências, pois cada um dos elementos, ao serem reunidos para construir uma unidade funcional maior, desenvolvem qualidades que não se encontram em seus componentes isolados (BERTALANFFY, 2008).

Segundo Hendel (2006, p. 1), design para livro é o que acontece dentro do livro e "irá chamar atenção ou não para si mesmo, isso vai depender do grau de consciência do leitor". Nota-se que é um tema complexo onde não possui muitas regras, e o profissional deve primeiramente compreender o texto e o público para o qual pretende comunicar, para em seguida definir a melhor forma de apresentar esse conteúdo que resultará na parte estética e visual.

Com isso, diante dos desafios atuais em propor melhorias tanto na qualidade de vida como na funcionalidade e estética de produtos e serviços, surge a questão há necessidade de adaptação e aprimoramento para ajustar estes livros aos vários dispositivos existentes? Esses suportes são complementares ou substitutivos entre si?

O objetivo geral deste artigo é compreender o design para livro, em diferentes suportes, por meio da abordagem sistêmica. Os objetivos específicos são: relatar um referencial teórico sobre o design para livro, abordando os diferentes suportes; identificar os elementos principais do livro referentes ao design, e os aspectos de interface e interação que estão relacionados ao design; e por fim, analisar esses elementos e aspectos em três livros e seus respectivos suportes, dentro de uma abordagem sistêmica. É importante salientar que são poucos os livros no formato "hiper", e por isso buscaram-se os que tivessem nos quatro suportes estudados.

A metodologia consiste na coleta de dados através da observação e análise comparativa do design de três livros: "Design, educação e tecnologia" (versão impressa e hipermidiática), "o livro depois do livro" (PDF) e o "101 indicadores da gestão" (e-book), de modo a verificar a interface e interação, utilizando notebooks, smartphones e iPad. Os critérios para análise foram definidos por meio da revisão bibliográfica, elucidados por Hendel (2006) e Haslam (2007), e os aspectos de interface (BATISTA; ULBRICHT, 2006) e interação (ROGERS; SHARP; PREECE, 2013) que estão relacionados ao mesmo, 
em seus diversos suportes. Os dados são apresentados em gráficos de radar e assim foi possível visualizar as diferenças e estabelecer qual suporte se encontra em melhor situação em relação ao design, interface e interação para os usuários desses materiais que são estudantes de graduação em cursos de Design.

Dessa forma, espera-se como resultado descobrir que os suportes e mídias se complementam ao invés de se substituírem, além de apontar as deficiências e diferenças no design para livro com a finalidade de auxiliar os profissionais da área no desenvolvimento dos futuros livros em suportes diferentes.

\section{ABORDAGEM SISTÊMICA NO PROCESSO DE DESIGN}

Neste tipo de abordagem os objetos dão lugar aos sistemas, quando presente no processo de design mostra como deve ser o ciclo produtivo de um objeto, entendendo que cada parte possui sua importância e deve estar inclusa dentro de um sistema maior. Como informa Morin (2005) que em vez das unidades simples, as unidades complexas; ao invés dos agregados formando corpos, os sistemas de sistemas.

O design busca a produção de coerência, e tem como critério de sucesso a satisfação da sociedade (BONSIEPE, 2011). Dessa maneira, as transformações desencadeadas pelo aperfeiçoamento das tecnologias visam compreender como cada parte de um estudo pode se inter-relacionar separadamente dentro de um sistema holístico, a fim de mudar as formas de pensar nos projetos que precisam ser flexíveis e incorporar o usuário como participante ativo.

Portanto, o design é um instrumento linguístico de comunicação que intervém no meio social com seus projetos focados na melhoria da qualidade de vida da sociedade e do mundo, buscando comunicar uma informação por meio de um produto ou serviço. Assim, informa Santos (2000) que propõe uma abordagem onde o design é considerado um sistema processador de informações (Figura 1).

Figura 1- Design como um sistema processador de informações

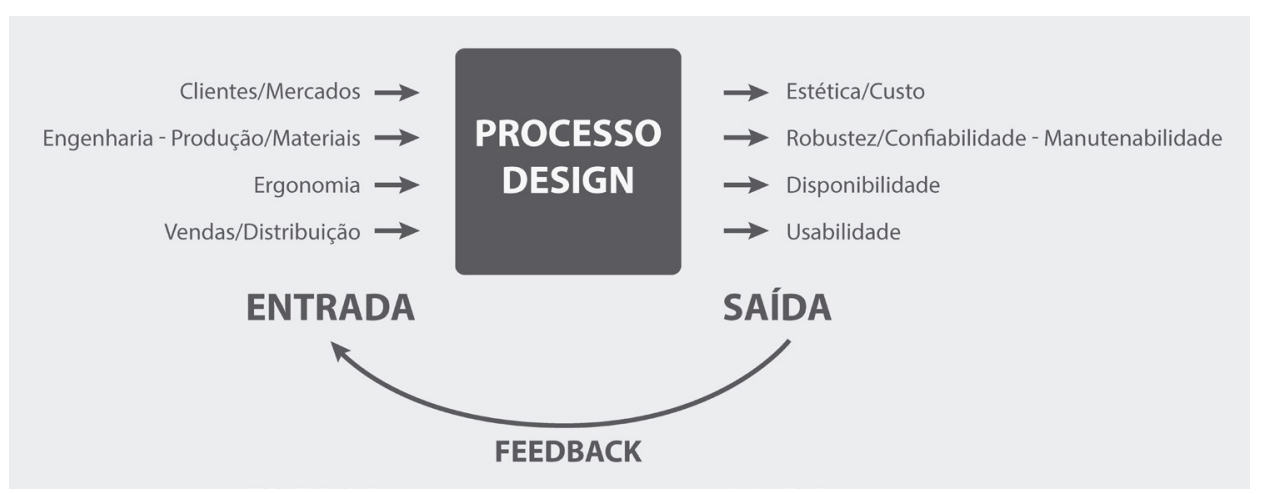

Fonte: Santos (2000, p. 24)

Projética, Londrina, v.8, n.2, p. 9-28, Jul./Dez. 2017 
A Figura 1 mostra que os dados de entrada ao serem processados resultam nas informações de saída, que são processadas pelo consumidor e surgem os informes de feedback que segundo Vasconcellos (2013, p. 115) "volta à entrada do sistema como informação" recomeçando todo o ciclo. Dessa forma, o resultado desse processo são informações "que irão identificar determinado produto ou empresa no mercado, posicionando-o com relação a concorrentes e consumidores" (SANTOS, 2000, p. 23). Na próxima seção será abordado sobre o design e o livro, relatando brevemente como o design de interação e interface se faz presente, além de abordar os elementos principais do design para livro e seus elementos.

\section{DESIGN E O LIVRO}

Essa nova visão de enxergar o todo no processo de design, fez com que o profissional se tornasse o "projetista de um processo estratégico que capacita a comunicação num formato visual" (MUNIZ; FIGUEIREDO, 2009). Por isso, antes de abordar sobre o design para livro será informado o que é design de interação e interface.

Para Rogers, Sharp e Preece (2013, p. 8) design de interação é quem cria "experiências de usuário que melhorem e ampliem a maneira como as pessoas trabalham, se comunicam e interagem". Dessa forma, nota-se que a interação com o livro vem sendo ampliada, pois antigamente a informação era apenas palavras, que se transformou em livro escrito manualmente com ilustrações, que virou um livro impresso com ilustrações, e agora está imergindo para o meio digital onde é possível inserir hipermídias (vídeos, músicas e jogos).

Dentro do design de interação, temos a interface que é "onde ocorre a interação" e "permeia o conteúdo formatado e o aplicativo de leitura", tendo a função de facilitar "a interação usuário e sistema", seja ele qual for, tanto impresso como digital (GONÇALVES; DAMÉ, 2013, p. 38). Batista e Ulbricht (2006) informa que o design de interface é uma atividade recente e multidisciplinar, onde a relação de suas áreas é ilustrada na Figura 2.

Por ser uma área ampla, serão analisadas as relacionadas com o design para livros que são: Comunicação (informação textual, visual e sonora); Linguagem gráfica (cor, textura, forma, tipografia); e a tecnologia envolvida na implementação de cada suporte.

Hendel (2006, p. 5) aborda que o termo design para livro é utilizado para se referir "ao que acontece dentro do livro e não em sua capa", ou seja no miolo, sendo este o foco do artigo. De acordo com Sehn (2009) antigamente à diagramação se resumia ao tamanho da letra utilizado, mas atualmente, na maioria dos casos, as pessoas apreciam uma diagramação que facilite seu ato de ler, aumentando o prazer de realizar a leitura. 
Figura 2- Multidisciplinaridade no Design de Interface

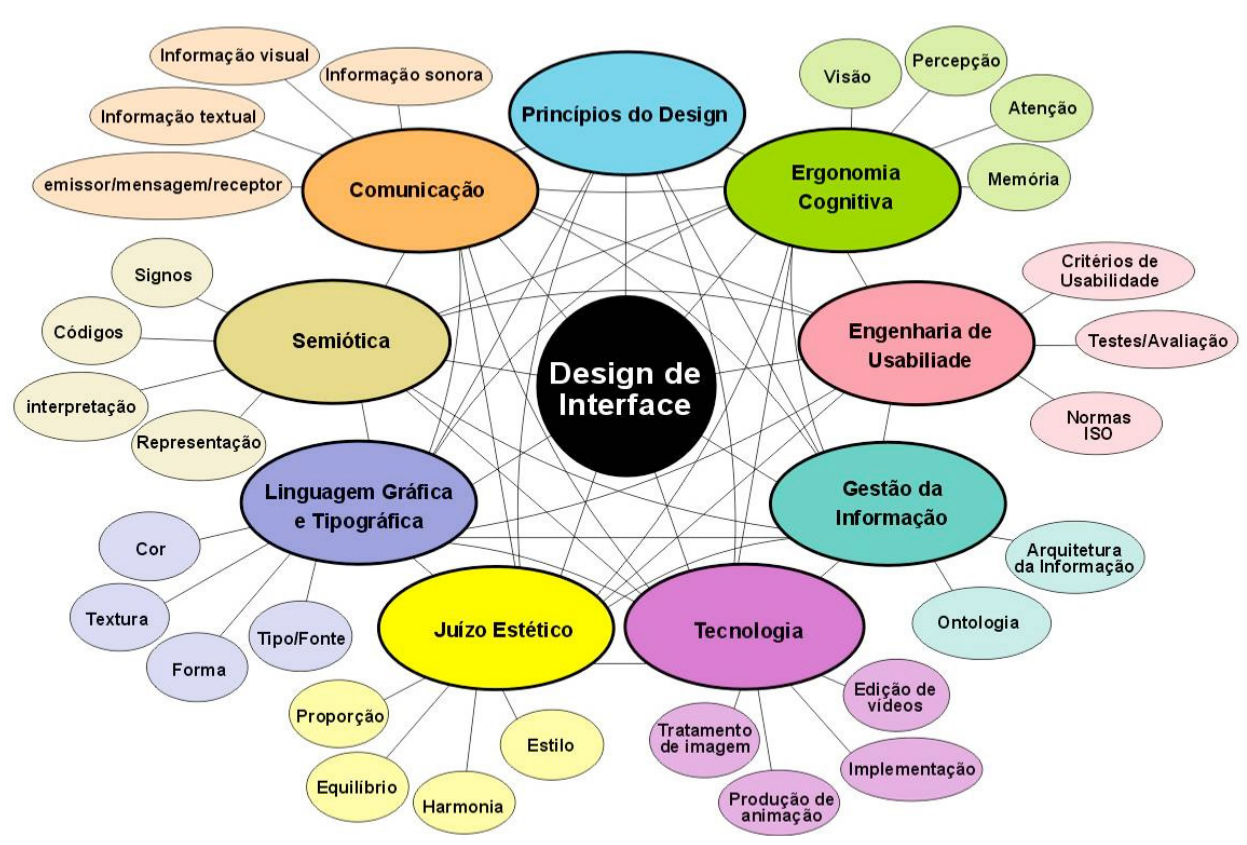

Fonte: Adaptado de Batista e Ulbricht (2006, p. 93)

Portanto, o designer tem o dever de fazer com que todos os elementos estejam interligados com o texto e seu assunto. Segundo Hendel (2006) existem alguns elementos principais no design para livro, são eles: formato, tipografia do texto e título, títulos correntes (ficam no rodapé), os fólios (números de página), a página de sumário, e ilustrações (tabelas, gráficos, fotografias, desenhos). Haslam (2007) informa que "a abertura e fechamento de capítulos" também são importantes.

O design começa com o formato - a forma física do livro (HENDEL, 2006) - que vai depender do seu suporte. Sehn (2014, p. 86) afirma que no impresso é definido o formato do papel, já no digital "a proporção da página e o peso do livro" são "dados pelo aparelho que o leitor estiver utilizando", podendo mostrar a página em tela cheia ou dentro de uma janela/margem alterando a sensação de tamanho.

Em seguida se define a tipografia do texto que é a parte principal do design para livro, "a base de todo o resto" (HENDEL, 2006, p. 36) e deve suprir todas as necessidades impostas por aquele material. $\mathrm{O}$ autor relata que existem três abordagens principais: tipografia neutra que não sugira época nem lugar; tipografia alusiva que remeta ao tempo passado; e tipografia nova que apresente o texto de forma única. Porém, para estabelecê-las é preciso saber "do que trata o livro e a quem é dirigido", pois uma tipografia pode "parecer normal para um grupo de leitores, mas extravagante para outro" (HENDEL, 2006, p. 33).

Contudo, escolher a tipografia para o título é um desafio, pois ela precisa ajudar a criar peso visual adequado em relação à página, tanto para títulos com duas palavras como para os com quinze palavras. O designer deve saber ajustar 
esses elementos que muitas vezes não vão se encaixar perfeitamente em todos os capítulos e páginas.

Títulos correntes é a repetição do nome do autor, título do livro e do capítulo nas páginas. "Em livro de organização complexa, ajudam o leitor a localizar um material rapidamente", e assim como os fólios (números das páginas) seu estilo e posição na página estão relacionados com o motivo de sua inclusão (HENDEL, 2006, p. 52).

A página de sumário, conforme Hendel (2006) e Sehn (2014), é diferente das demais e precisa conter hierarquia no texto (capítulos e subtítulos), podendo ser separado por seções ou diferenciada visualmente. As aberturas e fechamento de capítulos, tabelas, gráficos, diagramas, imagens e suas legendas também necessitam de um design diferenciado (SEHN, 2014). Portanto, as tabelas precisam ter "seu próprio design" e às fotografias (imagens ou ilustrações), integradas com o texto devem possuir legendas "diferenciadas tipograficamente do texto" e títulos (HENDEL, 2006, p. 60-61).

Dessa forma, a visão do design para livro relatada possui uma abordagem sistêmica por considerar desde o texto do autor (que definirá o assunto e a quem está comunicando), o processo do design para livro (definição do formato, o seu suporte e demais elementos), os aspectos da interface e como ela interage com o usuário, até chegar ao produto final, além do retorno que é o feedback de como foi a interação do produto com o usuário (Figura 3).

Figura 3- Design para livro como um sistema processador de informações

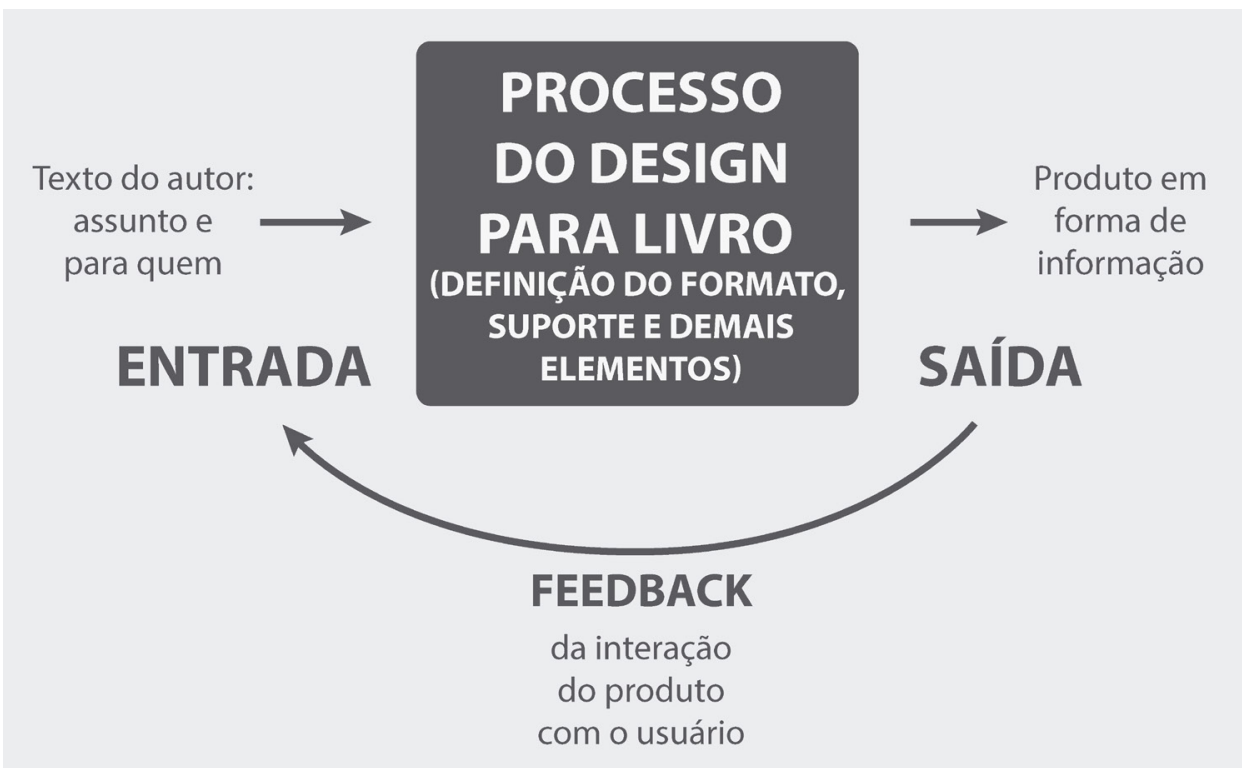

Fonte: Imagem desenvolvida pelos autores (2017) com base em Santos (2000) 
Por isso, segundo Muniz e Figueiredo (2009) optou-se pela abordagem onde o design é utilizado como um processo holístico, transferindo o foco do produto para o sistema do design para livro. Na sequência, será relatado o que é livro e as diferenças de seus suportes.

\section{LIVRO E SEUS SUPORTES: IMPRESSO, DIGITAL E HIPERMIDIÁTICO}

O livro é um objeto (material) inserido em uma dinâmica comercial e industrial que mantém características imateriais vinculadas ao conhecimento e saber disponibilizado pelo autor (GONÇALVES; DAMÉ, 2013). Além disso, a utilização do computador na produção do livro impresso substituiu a prensa tipográfica onde o modo de produção alterou-se, mas o produto permaneceu o mesmo. Dessa forma, os produtores tiveram que aprender a lidar com essas mudanças, mas o consumidor continuou recebendo um objeto semelhante (SEHN, 2014).

Com a evolução da tecnologia, novos meios e linguagens passaram a incorporar o livro impresso, introduzindo dimensões sensoriais, olfativas, sonoras, lúdicas, além do ingresso na área de multimídia, resultando nos livros digitais e hiper-livros que são suportes diferentes como era o papiro e o pergaminho (FERRARI; BARRETO, 2014), além de ocasionar mudanças na experiência do leitor. Os autores informam ainda que vivemos uma fase de transição entre o antigo e o novo mundo, o analógico e o digital, o celular e os smartphones, o livro impresso e o e-book, os velhos sistemas e as novas plataformas, e-readers, tablets, iPad, Kindle, Kobo.

Segundo Pluvinage e Stucchi (2015, p. 1) "o livro digital pode incorporar um 'texto' composto por elementos de várias mídias estáticas e dinâmicas", mantendo sua característica de texto. Não consiste na imitação do livro tradicional, é um instrumento de interação do usuário ou leitor com o conteúdo por nós que ligam - que são hipertextos - a navegação às mídias do conteúdo (GONÇALVES; DAMÉ, 2013).

Com base na discussão de alguns autores, Sehn (2014) informa que existem diferentes tipos de livros digitais: a) Customizável (permite que o visual do texto se ajuste conforme o equipamento e preferência do leitor; é acessado por softwares readers que possibilitam modificar o tamanho da letra, cores e tipografia, como os e-books); b) Layout fixo (o seu layout não se altera em função dos aparelhos e preferências do leitor); c) PDF (possui layout fixo em formato PDF); d) Digitalizado (digitalização do livro impresso); e) Multimídia (apresenta o texto, imagem estática, vídeos, animações e sons); f) Interativo (com conteúdos que exigem a ação do leitor para acioná-los, diferente das ações associadas à leitura). Possuem recursos adicionais como pesquisa no texto, tabelas e figuras interativas, hiperlinks para tópicos ou vídeos relacionados, botões interativos, áudios que podem facilitar a compreensão (MCGOWAN; STEPHENS; BRADLEY, 2009; PLUVINAGE; STUCCHI, 2015). 
Dessa forma, o hiper-livro (é hipermidiático, segundo Sehn (2014) e Mucheroni e André (2013) são os livros multimídia e interativo) composto pelo texto junto de vídeos, músicas, games e outra mídias dinâmicas, além de exigir a ação do leitor para acionar o conteúdo. Ele contém novos recursos como dicionários integrados, guias de pronunciação e simulação interativa, possibilitando que os leitores interajam com o conteúdo do livro mais ativamente que apenas lendo-os (NELSON, 2008).

Aos poucos a indústria editorial vai se diferenciado da impressa "e pela primeira vez na história é possível pensar numa 'edição' multimodal, ou seja, som e textos dentro de uma única 'publicação', ter diretores de arte, de música e de vídeos" (MUCHERONI; ANDRÉ, 2013), tornando-se necessário ter, além do designer, um profissional que entenda de som, outro de vídeo e assim sucessivamente. A próxima seção aborda as etapas metodológicas e as delimitações da pesquisa.

\section{METODOLOGIA}

Quanto à sua finalidade, este trabalho é classificado como exploratório, pois objetiva prover maior compreensão acerca do design para livro e seus suportes (GIL, 2010). A partir de um estudo exploratório sobre a evolução dos livros e seus suportes, realizado de setembro à outubro de 2015 nas bases de dados GOOGLE ACADÊMICO e CAPES, percebeu-se a oportunidade de analisar e comparar o design para livro dos diferentes suportes existentes, verificando como é sua interface e interação. Na sequência foi efetuado um levantamento bibliográfico (GIL, 2010), realizado em novembro de 2015, baseado em informações secundárias constituídas de livros, artigos e demais materiais disponibilizados em bases de dados eletrônicos (GOOGLE ACADÊMICO e (APES).

A pesquisa classifica-se como descritiva qualitativa (GIL, 2010), buscando observar o design de três livros em quatro suportes diferentes, além de analisar e comparar os principais elementos do design para livro, e os aspectos de interface e interação que estão relacionados ao mesmo (Figura 4). A amostra é composta por três livros da área de Design (Design, tecnologia e educação; O livro depois do livro; e 101 indicadores da gestão) que podem ser utilizados na graduação, foram selecionados por critério amostral não probabilístico por conveniência em relação à disponibilidade gratuita e em duas opções de suportes diferentes.

A técnica de coleta de dados utilizada foi a observação e análise comparativa do design de três livros realizada por duas especialistas da área do design em dezembro de 2015, o instrumento da coleta de dados foi um formulário digital desenvolvido no Word composto pelos elementos que precisam ser analisados (vide Figura 5). 


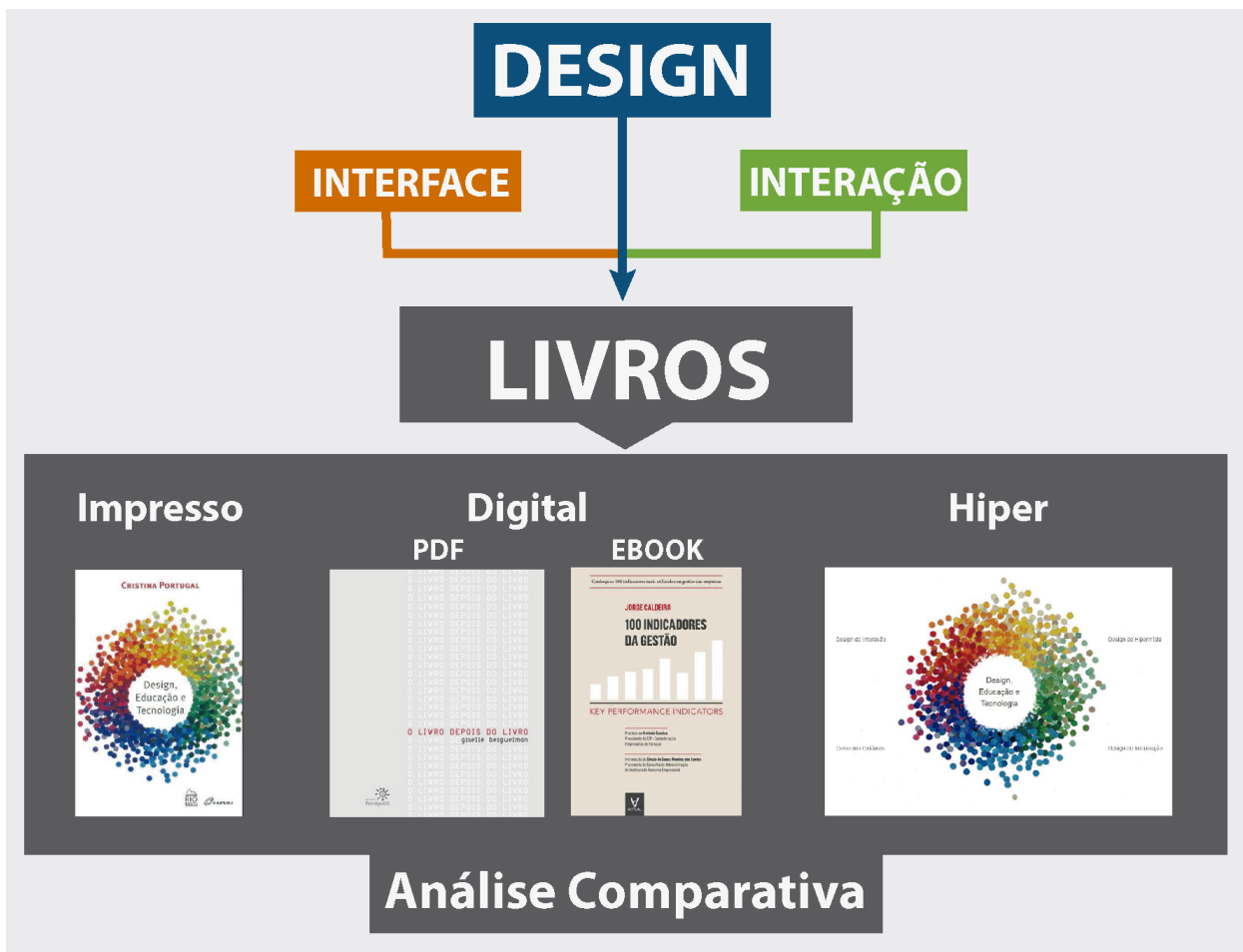

Fonte: Elaborado pelos autores (2017)

Os critérios para análise foram definidos por meio da revisão bibliográfica, onde foram identificados quais são os principais elementos de design (HENDEL, 2006; SEHN, 2009, 2014; HASLAM, 2007) e interface (BATISTA; ULBRICHT, 2006) de um livro que precisam ser analisados, e como a interação (ROGERS; SHARP; PREECE, 2013; SEHN, 2014) se faz presente em cada suporte (vide Figura 5). As análises dos livros digitais ("O livro depois do livro" em formato PDF; "101 indicadores da gestão" em formato ebook; e "Design, tecnologia e educação" em formato hiper-livro) foram realizadas no notebook, smartphone e iPad, além disso, é importante relatar que o ebook foi analisado no aplicativo eReaders da saraiva instalado nos aparelhos.

Figura 5- Elementos de Design, Interface e Interação analisados

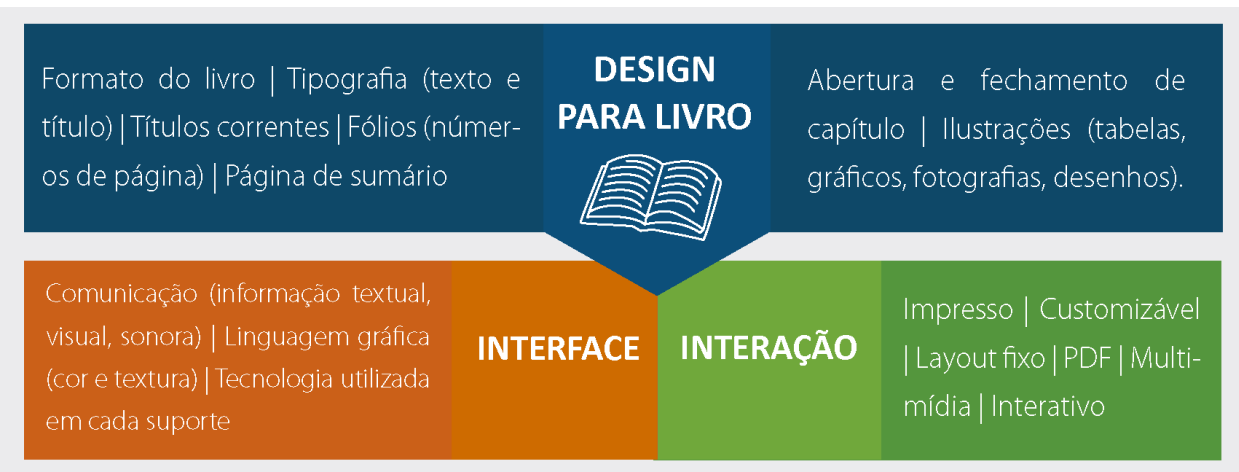

Fonte: Elaborado pelos autores (2017) 
Os dados são apresentados em gráficos de radar, conforme a análise realizada pelos autores Ourives et al. (2016), em cinco níveis: excelente (nota 5, não tem nada para modificar); muito bom (nota 4), satisfatório (nota 3), deficiente (nota 2), nesses três níveis é necessário fazer alterações; insuficiente (nota 1) quando os elementos não existem. Dessa forma, é possível visualizar a diferença e estabelecer qual suporte se encontra em melhor situação em relação ao design, interface e interação. A próxima seção é composta pela análise e apresentação dos resultados obtidos na pesquisa.

\section{DISCUSSÃO DOS RESULTADOS}

Nesta seção serão relatados os resultados obtidos na análise em três etapas: Design, Interface e Interação. Além disso, "O livro depois do livro" (BEIGUELMAN, 2003) e "101 indicadores da gestão" (não possui versão gratuita) possuem versão impressa e digital praticamente iguais, com o mesmo design, por isso será analisado apenas a versão digital de ambos. Já o livro "Design, tecnologia e educação" serão observadas as versões impressa e hiperlivro (PORTUGAL, 2013), pois possuem design diferentes.

Referente ao design, o hiper-livro está em melhor situação comparado aos demais, por possuir apenas três pontos fracos relativos aos fólios (e), fechamento de capítulo (h) e tabelas (i) que não comprometem o seu design (vide Figura 6).

Figura 6- Análise dos elementos de design

\section{DESIGN}
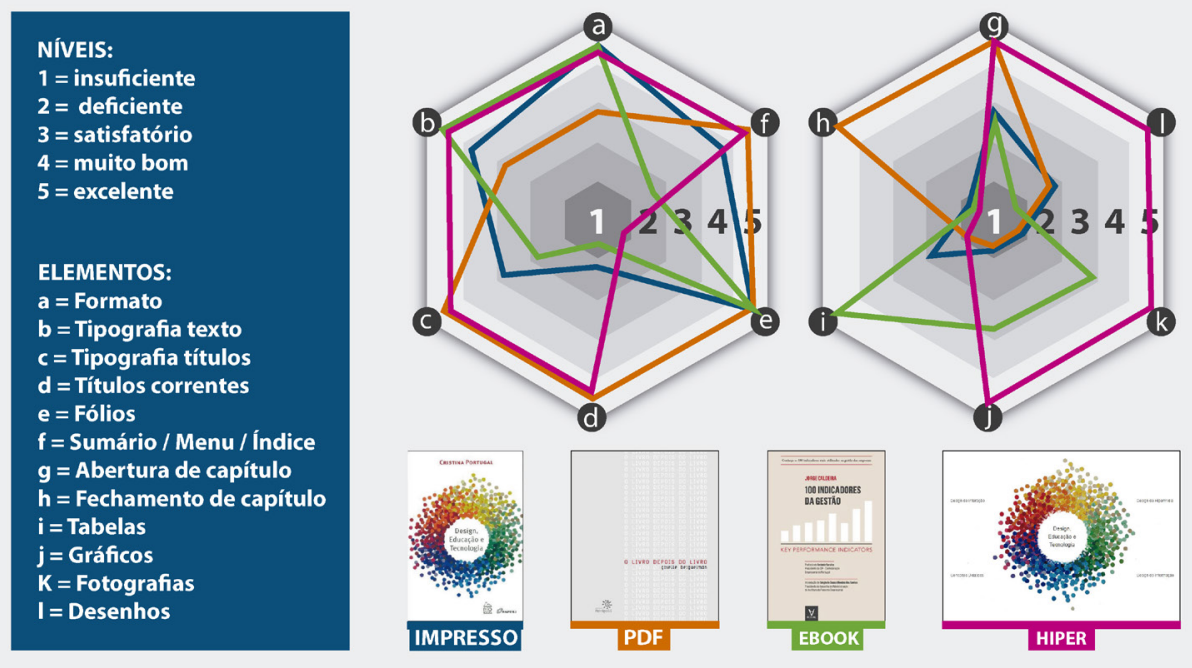

Fonte: Elaborado pelos autores (2017) com base em Ourives et al. (2016)

a) Formato: $O$ impresso e hiper são retangulares, sendo o primeiro na vertical com dimensões de $21 \times 14 \mathrm{~cm}$ e 143 páginas, tornando-o pequeno e fácil de carregar para qualquer lugar, já o segundo na horizontal, não é possível identificar sua dimensão em altura e largura, mas está adequado para o meio 
em que será visualizado. O ebook não possui dimensão em altura e largura, e número de páginas específicas por ter layout flexível que varia de acordo com o tamanho da tela. O PDF é quadrado, nas dimensões 19,97x19,97cm e com 96 páginas, o que não é muito adequado ao meio onde será visualizado (as telas são retangulares), por isso é o único que ficou no nível satisfatório, os demais foram avaliados como excelente.

b) Tipografia texto: Os livros, com exceção do PDF, são legíveis e adequados ao tipo de suporte, tornando a leitura agradável e a tipografia utilizada foi a mesma em todo livro. O ebook (na maior parte é neutra, com serifa e geométrica; já nos gráficos é semelhante, mas sem serifa) e hiper (neutra, sem serifa, totalmente geométrica e reta) foram avaliados como excelente por não necessitarem de nenhuma alteração. O livro impresso (neutra, sem serifa, geométrica, com alguns elementos mais arredondados tornando-a mais estilizada) foi avaliado como muito bom, pois possui uma deficiência nos caracteres de números (alguns ficam deslocados mais para cima ou para baixo) transmitindo a sensação de defeito. Já o PDF foi avaliado como satisfatório por possuir tipografia nova (apresenta o texto de forma única), serifada, que imita a interface dos computadores, tornando a leitura um pouco difícil por não ser muito legível.

c) Tipografia título: O hiper (possui destaque no subcapítulo com tamanho maior, em seguida enxergam-se os títulos em tamanho menor, e na sequência os subtítulos e o texto) e o PDF (os títulos encontram-se em tamanho maior e na cor vermelha destacando-se do texto, e mesmo a tipografia não sendo legível não compromete a leitura) foram avaliados como excelente, pois possuem peso visual adequados transmitindo hierarquia nas informações. O impresso ficou classificado como satisfatório, pois mesmo possuindo peso visual adequados no capítulo (em relação ao subcapítulo) e subtítulo (referente ao título), informando a hierarquia corretamente, os subcapítulos possuem o mesmo peso visual que os títulos (sem indicação do número "IV.I Subcapítulo" como é mostrado no sumário). O mesmo acontece entre os subtítulos e sub-subtítulos do capítulo 4 (notou-se devido ao sumário), isso dificulta o entendimento e compromete a hierarquia de informação. E o ebook foi avaliado como deficiente, uma vez que o título (maior e em caps look) e o subtítulo (também em caps look, em tamanho menor, mas em negrito) estão com o mesmo peso visual criando conflito de hierarquia na informação.

d) Títulos correntes: O PDF (informa o nome da autora, e o título do livro junto do capítulo) e o hiper (não possui conforme os padrões, mas indica no topo o nome do capítulo com mesma funcionalidade) classificaram-se como excelente por comunicarem ao leitor em qual capítulo ele está. O livro impresso (informa o nome do autor e do livro), não possuindo funcionalidade, por isso foi avaliado como deficiente, e o ebook como insuficiente. 
FIGUEIREDO, Luiz Fernando Gonçalves de et al.

e) Fólios (números de páginas): Todos os livros, com exceção do hiper que não possui (não é possível identificar o tamanho do seu volume), foram classificados como excelente já que ajuda a situar o leitor em qual página está e quantas faltam para acabar a leitura. Porém, no ebook elas variam conforme o tamanho da tela, por possuir layout customizável.

f) Sumário/menu/índice: O hiper (possui menu inicial com a mesma funcionalidade, mas a numeração das páginas é substituída pelos hiperlinks, contem ilustração no centro junto ao nome do livro, ao redor possui os títulos dos capítulos, que ao colocar o mouse sobre cada um ficam em sua respectiva cor mostrando seus títulos, basta clicar neles para acessar o conteúdo) e o PDF (tem sumário composto pelos capítulos e suas respectivas páginas; está dividido em duas cores, a parte referente aos títulos tem fundo cinza e tipografia em branco, e a outra relativa à numeração tem fundo branco e tipografia em vermelho; a numeração das páginas se destacam pela cor) foram avaliados como excelente, já que possuem peso visual adequado tendo uma boa hierarquia. $O$ livro impresso (com sumário dividido em quatro capítulos com suas respectivas páginas) classificou-se como muito bom porque mesmo possuindo hierarquia nas informações, a composição gráfica pode ser aperfeiçoada (contem metade de um círculo onde dentro está escrito "Sumário"). Já o ebook está avaliado como deficiente pelo fato de possuir apenas um índice (no final com hiperlinks que te direcionam para as páginas) sem hierarquia de informação.

g) Abertura de capítulo: O hiper (página com breve introdução; possui uma tag com o nome do capítulo no topo; abaixo um menu com o nome dos títulos do capítulo, em seguida mostra o texto com título e ilustrações de apoio; e na parte inferior contém uma seta para ir para a próxima página) e o PDF (é uma página com ilustrações composta por desenhos padronizados) foram avaliados como excelentes por apresentarem páginas totalmente diferente das demais e bem elaboradas. Já o impresso e o ebook ficaram classificados como satisfatório porque podem ser aperfeiçoados, no primeiro é indicada pela metade de um círculo com a palavra "Capítulo x" dentro, e no segundo a página possui o título do capítulo, uma fotografia e subtítulos com hiperlinks.

h) Fechamento de capítulo: Apenas o PDF possui e foi avaliado como excelente, já que contém notas de referências bibliográficas, com hiperlinks referentes ao capítulo tratado, auxiliando no aprendizado e diferenciando-se das demais páginas.

i) Tabela; j) Gráficos; k) fotografias; I) desenhos (ilustrações): Neste item o hiper está em melhor situação com classificação excelente (com exceção do elemento tabela que não possui), uma vez que contém muitos gráficos, fotografias (algumas em tons escuros indicando tecnologia), imagens (com tipografias orgânicas ou neutras) e desenhos (de objetos desenhados a mão; realísticos de personagens animados, alguns com lettering estilizado; outros feitos com letras que formam uma palavra) coloridos, em preto e branco, geométricos e orgânicos. 
O ebook classifica-se como excelente em relação às tabelas, já que elas se adequam com o aumento da fonte, estão legíveis e possuem hierarquia na informação; já os gráficos (nas versões para o smartphone e iPad não estão no tamanho adequado com boa visualização e legibilidade) e as fotografias (expostas no início dos capítulos, na horizontal e remetendo ao assunto respectivo ao capítulo) estão avaliados como satisfatórios porque podem ser aperfeiçoados; e os desenhos como insuficientes (não possui). O impresso e o PDF são enfraquecidos nesses elementos e devem aperfeiçoa-los, dessa forma: o primeiro foi avaliado como deficiente por conter poucas tabelas e desenhos, e insuficiente por não apresentar gráficos e fotografias durante o texto; já o segundo encontra-se classificado como deficiente referente aos desenhos (que são padronizados e inspirados nas interfaces dos computadores; possuem textos repetitivos e colagens; e estão presentes apenas nas aberturas de capítulo) e insuficiente relativo às tabelas, gráficos e fotografias.

Em relação à Interface o hiper-livro também ficou em melhor situação quando comparado com os demais, mas mesmo assim possui dois pontos enfraquecidos como as texturas (e) e tecnologia do suporte (f). É importante mencionar que a tipografia e a forma não foram abordadas por já terem sido mencionadas no design. Além disso, todos os livros possuem informação textual (a) sendo classificados como excelente, pois, como foi visto na seção "Design e o Livro", para ser considerado livro precisa conter textos (Figura 7).

Figura 7- Análise dos aspectos relacionados a interface

\section{INTERFACE}

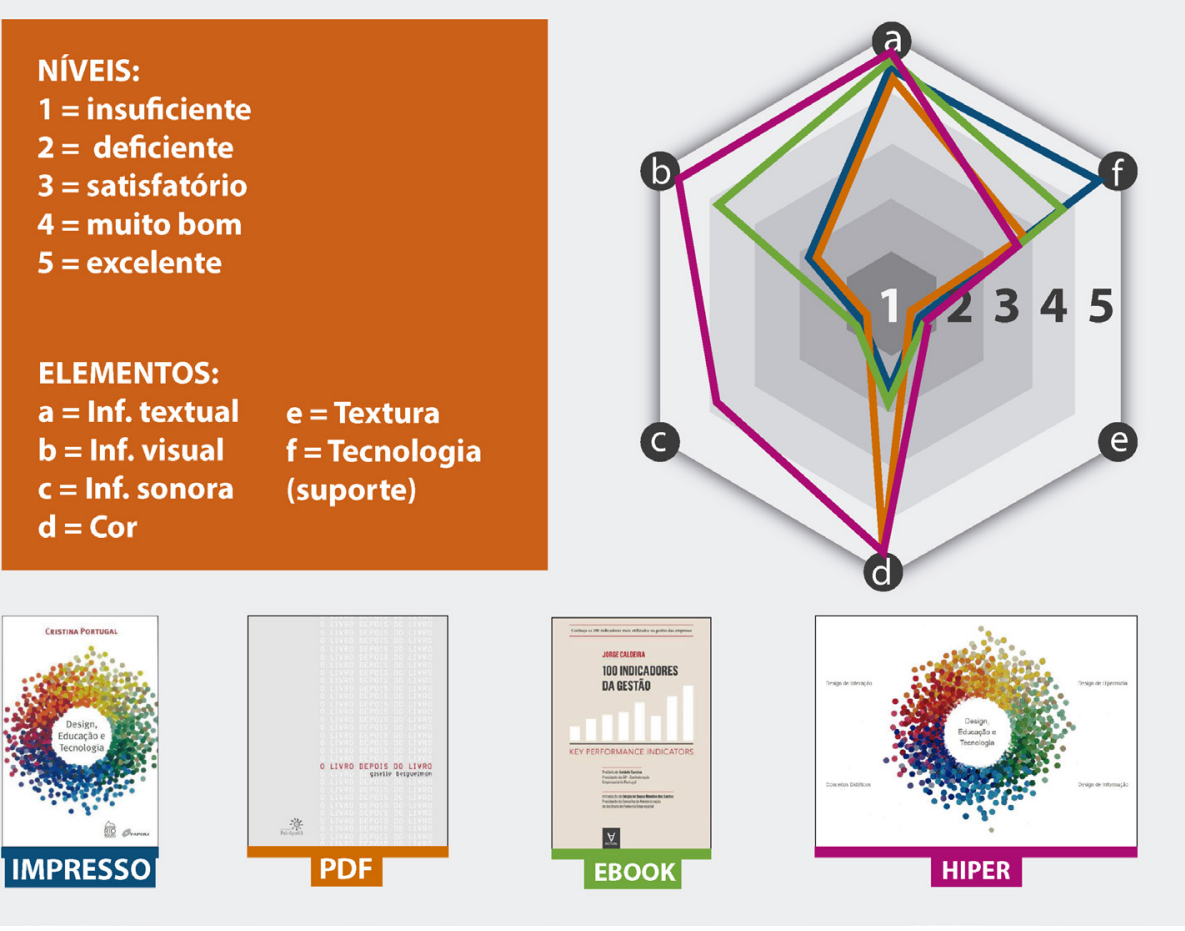

Fonte: Elaborado pelos autores (2017) com base em Ourives et al.

(2016) 
FIGUEIREDO, Luiz Fernando Gonçalves de et al.

b) Inf. visual; e

c) Inf. sonora (comunicação): O hiper classifica-se como excelente relativo à informação visual (imagens estáticas, como gráficos, infográficos, desenhos, fotografias e etc; e em movimento, como vídeos, animaç̃̃es 2D com objetos, animação 3D e etc) já que não precisa de modificações, e muito bom quanto a informação sonora (representada por trilha sonora e vozes de pessoas/ personagens) por possuir uma deficiência nas falas, na maioria, dos vídeos que estão em outro idioma (inglês e francês) sem legendas e esse livro é destinado para os brasileiros, então se os alunos não dominarem os mesmos, os vídeos são desnecessários, por isso deveria ser colocado legendas em português. O ebook, impresso e PDF não possuem informação sonora sendo avaliados como insuficiente, referente a informação visual: o primeiro classifica-se como muito bom, pois contem várias imagens estáticas (tabela, gráfico, fotografia), mas precisam ser aperfeiçoadas; já o segundo (desenhos geométricos e tabelas) e terceiro (desenhos), foram avaliados como deficientes por possuírem poucas imagens estáticas durante o texto, esse recurso podia ter sido mais explorado, como no hiper-livro, mesmo que tivessem de ser preto e branco, tornaria a leitura e a interação mais agradável.

d) Cor; e) Textura (linguagem gráfica): Todos os livros foram avaliados como insuficientes em relação a textura. Referente a cor: o hiper (cada capítulo possui uma cor que o sinaliza e diferencia dos demais; design de interação na cor laranja claro; design de hipermídia na cor verde claro; design de informação na cor azul claro; e conceitos didáticos na cor roxa clara) e o PDF (predominância das cores branco, preto, vermelho e cinza) classificam-se como excelentes, pois ambos são coloridos tornando a leitura mais agradável; o impresso e o ebook avaliam-se como deficientes por serem em preto e branco.

f) Tecnologia (suporte): O livro "design, tecnologia e educação (versão impressa)" é físico (impresso em papel sulfite com impressora Offset); suporta informação visual estática e textual (apesar disso é o mais utilizado até hoje); não varia o seu meio de visualização (como acontece no digital), por isso sua visibilidade é sempre igual e adequada a sua tecnologia favorecendo a leitura que, dependendo do tipo de leitor, é menos cansativa no papel; devido a esses motivos classifica-se como excelente. O ebook "101 indicadores da gestão" possui tecnologia digital customizável; suporta informação textual, visual estática e hiperlinks; por ter layout flexível, essa tecnologia se adapta ao tamanho de todas as telas (smartphone, iPad e notebook), o que favorece e torna sua visualização apropriada para todos os tamanhos de telas; foi avaliado como muito bom pelo fato de ainda necessitar de aperfeiçoamento. Já "o livro depois do livro" (possui tecnologia digital voltada para o software PDF que possui layout fixo, suporta informação textual, visual estática e hiperlinks) e o "design, tecnologia e educação" (versão hiper é uma página html que abre no navegador de internet, foi utilizado o google chrome, e suporta informação textual, visual estática e em movimento, sonora e hiperlinks) classificam-se como satisfatório 
já que a tecnologia de ambos precisa de mais aperfeiçoamento que os demais, mesmo o hiper sendo mais interativo que os outros (no caso deste livro possui alguns problemas de visualização), devido aos fatos: do primeiro, ter uma boa visualização apenas no smartphone e no iPad (a forma das páginas, na vertical, se enquadra ao formato das telas) quando comparado com o notebook (por ser horizontal, há a necessidade de ampliar até que a página se enquadre na tela); o segundo possui uma boa visualização e legibilidade no notebook e iPad (apesar disso, neste meio, o livro não funciona muito bem, pois ao clicar em um capítulo no menu os títulos não abrem, não sendo possível acessar seu conteúdo), o menu e suas páginas se ajustam na tela perfeitamente, já no smartphone isso não acontece e é necessário utilizar a barra de rolagem para visualizar todo o conteúdo.

Em relação à Interação nenhum livro está na melhor situação, já que cada tipo de suporte tem suas vantagens e desvantagens, sua escolha depende do que o leitor procura e considera mais importante durante a leitura (vide Figura 8).

Figura 8- Análise dos aspectos relacionados a interação

\section{INTERAÇÃO}

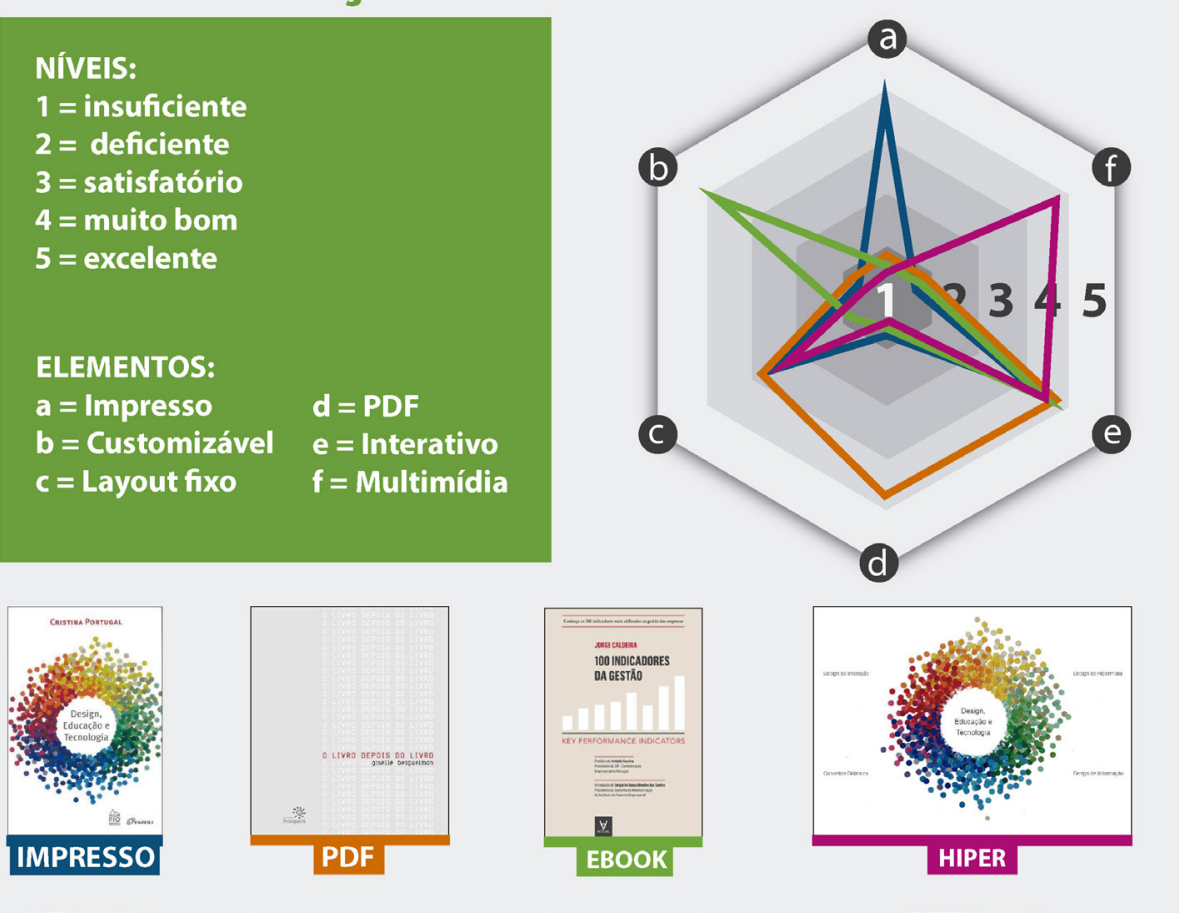

Fonte: Elaborado pelos autores (2017) com base em Ourives et al. (2016)

a) Impresso: Apenas o "design, tecnologia e educação" se enquadra, já que possui tecnologia impressa, classificando-se como muito bom, pois não é possível pesquisar palavras específicas rapidamente como nos digitais. A interação se faz presente no folhear de páginas, no cheiro do livro, na textura do 
FIGUEIREDO, Luiz Fernando Gonçalves de et al.

papel, além de ser possível fazer anotações à caneta, marcar trechos, colocar marcador de páginas, dobrar a folha e etc.

b) Customizável: Comprende somente o "101 INDICADORES DA GESTÃO (ebook)" que possui maior interatividade no aplicativo do smartphone e iPad do que no notebook, já que: no primeiro é possível trocar a tipografia, a cor de fundo e da fonte, o modo de visualização, ajustar a luminosidade da tela, regular o tamanho da margem, espaçamento entrelinhas, travar a tela para não rotacionar, buscar palavras no texto, grifar texto e borracha para apaga-los, fazer anotações, capturação de tela, adicionar nota, entre outros ajustes; já no segundo é possível apenas aumentar a fonte, fazer anotações e marcações. Por esses motivos foi avaliado como muito bom, pois necessita de aperfeiçoamento.

c) Layout fixo: Todos, com exceção do ebook, possuem layout fixo (não é possível alterar o tamanho e tipografia das letras, cor e etc.) e foram avaliados como satisfatório por possuírem menos ajustes.

d) PDF: Apenas o "O LIVRO DEPOIS DO LIVRO" é considerado PDF e possui interatividade relacionada a este formato, no fechamento de cada capítulo há um subtítulo chamado "Bookmarks" onde constam referências bibliográficas, em hiperlinks, para leitura complementar correspondente a cada assunto tratado. Quando visualizado no notebook, smartphone e iPad, basta clicar em cima do hiperlink que este abrirá em uma nova janela o link selecionado. Ele classifica-se como satisfatório.

e) Interativo: Todos são considerados, pois para as ações serem executadas o leitor precisa acioná-las, e avaliados como satisfatórios já que sua interatividade varia muito, por este motivo um ser melhor que o outro vai depender do tipo de leitor. No impresso é possível fazer o que desejar, mas para pesquisar uma palavra ou assunto é preciso folhear página por página, já nos digitais é possível fazer apenas o que o software permite. No PDF as atividades que precisam ser executadas pelo leitor são adicionar notas, marcar trechos, pesquisar termos específicos e colocar um marcador na página. O ebook possui maior interatividade no aplicativo do smartphone e iPad do que no notebook, por terem mais opções de ajustes. E no hiper o leitor precisa clicar: nos vídeos para assisti-los; nas setas para ir de uma página a outra, para voltar para o menu principal ou para entrar em outro subtítulo; além de botões para acessar a bibliografia (ícone em forma de livro) e acessar os livros relacionados com o conteúdo (ícone de +); porém, não é possível adicionar marcações, notas, grifar trechos e pesquisar palavras como nos demais. Mesmo assim, a interação do hiper é mais dinâmica e descontraída, em relação aos demais, o que prende a atenção do leitor fazendo o mesmo perder a noção de quanto tempo ele está lendo e quanto tempo ainda falta, além disso, ele acaba não se importando com quantas páginas faltam, como acontece nos outros. 
f) Multimídia: Apenas o hiper é considerado por possuir vídeos, gifs, animações, ilustrações, fotografias, ou seja, todas as mídias possíveis e existentes até então.

A próxima seção aborda as conclusões da revisão bibliográfica e dos resultados.

\section{CONCLUSÃO}

Analisar os elementos e aspectos de um determinado sistema ou produto através de uma abordagem sistêmica permite compreender cada parte do processo, suas inter-relações e sua função dentro de um sistema maior. Além disso, percebe-se como o pensamento sistêmico se faz presente no design, pois além da entrada, processo e saída de informações, ainda possui o feedback da interação do usuário com o produto ou serviço.

Dentro deste pensamento, o trabalho identificou e analisou o design de três livros, os aspectos de interface e interação, bem como os elementos destes em três suportes diferentes, dentro de uma abordagem sistêmica. O intuito foi de pesquisar e sintetizar em um trabalho, considerações a respeito do design para livros, para que fosse possível uma melhor qualidade de leitura e visualização de informações por parte dos estudantes de cursos de graduação na área do Design.

Sendo assim, a abordagem sistêmica considerou desde o texto do autor, o processo do design para livro, os aspectos da interface e como ela interage com o usuário, até chegar ao produto final, além do feedback de como foi a interação do produto com o usuário. Com isso, é notável que os livros digitais e hiper-livro precisam de aprimoramento para se ajustar aos vários dispositivos existentes hoje em dia e também se verificou que os suportes (versão impressa, digital e hipermidiática) e mídias se complementam e não se substituem.

Vale ressaltar que esta pesquisa foi o início de um estudo que pretendeu compreender o design do livro e seus suportes. Portanto, fez-se necessário a construção de um conhecimento através de estudo teórico sobre o assunto, a identificação dos principais elementos, bem como a interface e interação envolvida no design.

O artigo pode ser usado para orientar estudantes, designers e pesquisadores interessados sobre estas questões e para estudos futuros, esta pesquisa pode ser estendida para obter mais informações e formas de implementar tanto o livro digital e hiper-livro, quanto os outros tipos de materiais didáticos por um olhar sistêmico. 


\section{REFERÊNCIAS}

BATISTA, C. R.; ULBRICHT, V. R. Discussões sobre o perfil do designer de interfaces web. Design em Foco, Salvador, v. 3, p. 87-101, 2006. Disponível em: <http://www.redalyc.org/articulo.oa?id=66111515007>. Acesso em: 24 nov. 2015.

BEIGUELMAN, G. O livro depois do livro. São Paulo: Peirópolis, 2003. Disponível em: <http://www.desvirtual.com/thebook/o_livro_depois_do_livro. pdf>. Acesso em: 24 nov. 2015.

BERTALANFFY, L. V. Teoria geral dos sistemas: fundamentos, desenvolvimento e aplicações. 3. ed. Petrópolis: Vozes, 2008.

BONSIEPE, G. Design, cultura e sociedade. São Paulo: Blucher, 2011.

FERRARI, M. A.; BARRETO, C. V. A. Impresso x digital: uma reflexão sobre a transição do meio impresso para o meio digital nos processos comunicacionais. Organicom, São Paulo, v. 11, n. 21, p. 19-30, 2014. Disponível em: <http://www.revistaorganicom.org.br/sistema/index.php/organicom/ article/view/782>. Acesso em: 24 set. 2015.

GIL, A. C. Como elaborar projetos de pesquisa. 5. ed. São Paulo: Atlas, 2010.

GONÇALVES, B. S.; DAMÉ, G. M. Características da leitura em um livro eletrônico interativo: uma revisão integrativa. Texto Digital, Florianópolis, v. 9, p. 35-51, 2013.

HASLAM, A. O livro e o designer Il: como criar e produzir livros. São Paulo: Rosari, 2007.

HENDEL, R. O design do livro. 2. ed. São Paulo: Ateliê Editorial, 2006.

MCGOWAN, M. K.; STEPHENS, P. R.; BRADLEY, C. W. Student perceptions of electronic textbooks. Issues in Information Systems, [S. I.], v. 10, n. 2, p. 459465, 2009. Disponível em: <http://www.iacis.org/iis/2009/P2009_1299. pdf>. Acesso em: 24 nov. 2015.

MORIN, E. O método 1: a natureza da natureza. Tradução de llana Heineberg. Porto Alegre: Sulina, 2005. 
MUCHERONI, M. L.; ANDRÉ, J. N. Proposta de análise do ebook em 4 aspectos. In: ENCONTRO NACIONAL DE PESQUISA EM CIÊNCIA DA INFORMAÇÃO, 14., 2013, Florianópolis. Anais... Florianópolis, 2013. Disponível em: <http://repositorios.questoesemrede.uff.br/repositorios/ handle/123456789/2499>. Acesso em: 16 nov. 2015.

MUNIZ, M. O.; FIGUEIREDO, L. F. G. Redefinindo o design: por uma abordagem sistêmica. Actas de Diseño, Palermo, v. 1, p. 215-227, 2009. Disponível em: <http://fido.palermo.edu/servicios_dyc/encuentro2007/02_ auspicios_publicaciones/actas_diseno/articulos_pdf/ADC039.pdf>. Acesso em: 1 nov.2015.

NELSON, M. R. E-books in higher education: nearing the end of the era of hype? Educause Review, [S. I.], v. 43, n. 2, p. 40-56, 2008. Disponível em: <https://intranet.ebc.edu.mx/contenido/faculty/archivos/impacto_ cultural_140512.pdf>. Acesso em: 24 nov. 2015.

OURIVES, E. A. A. et al. Design universal: banheiros inclusivos de shoppings de grande porte. Blucher Design Proceedings, [S. I.], v. 2, n. 9, p. 3169-3180, 2016.

PLUVINAGE, J. F.; STUCCHI, P. Análise da narrativa dos livros didáticos digitais. In: CONGRESSO BRASILEIRO DE CIÊNCIAS DA COMUNICAÇÃO, 38., 2015, Rio de Janeiro. Anais... Rio de Janeiro: Itercom, 2015. Disponível em: <http://portalintercom.org.br/anais/nacional2015/resumos/R10-1111-1.pdf>. Acesso em: 24 set. 2015.

PORTUGAL, C. Design, educação e tecnologia. Rio de Janeiro: Rio Books, 2013. Disponível em: < http://design-educacao-tecnologia.com/index.html>. Acesso em: 24 set. 2015.

ROGERS, Y.; SHARP, H.; PREECE, J. Design de interação: além da interação humano-computador. Tradução de Isabela Gasparini. Porto Alegre: Bookman, 2013.

SANTOS, F. A. O design como diferencial competitivo: o processo de design desenvolvido sob o enfoque da qualidade e da gestão estratégica. 2. ed. Itajaí: Univali, 2000.

SEHN, T. C. M. As possíveis configurações do livro nos suportes digitais. 2014. 272 f. Dissertação (Mestrado em Comunicação e Informação) - Universidade Federal do Rio Grande do Sul, Porto Alegre, 2014. Disponível em: <http://www. lume.ufrgs.br/handle/10183/97246?locale=pt_BR>. Acesso em: 20 nov. 2015. 
FIGUEIREDO, Luiz Fernando Gonçalves de et al.

SEHN, T. C. M. O livro como objeto de desejo. 2009. 224 f. Trabalho de Conclusão de Curso (Graduação em Design Gráfico) - Universidade Federal de Pelotas, Pelotas, 2009. Disponível em: < http://escritoriodolivro.com.br/ leitura/objeto\%20desejo.pdf>. Acesso em: 24 nov. 2015.

VASCONCELLOS, M. J. E. Pensamento sistêmico: o novo paradigma da ciência. 10. ed. Campinas: Papírus, 2013. 